\title{
Editorial
}

\section{From Valencia to Porto: en route to CIFI 2020}

\author{
Fermín Valera Garrido ${ }^{1}$ Francisco Minaya Muñoz ${ }^{2}$ \\ 1 Vice-president of the Organizing Committee at the III International \\ Conference of Invasive Physical Therapy, 2018, Valencia, Spain \\ 2 President of the Scientific Committee at the III International \\ Conference on Invasive Physical Therapy, 2018, Valencia, Spain
}

Rev Fisioter Invasiva 2019;2:49.

"If they copy you, it means that you have found a successful model.

If on top of this you are criticized, it means they don't even know how to copy you"

\section{Anonymous}

The International Conference on Invasive Physical Therapy began as an original initiative created by MVClinic in 2014, as pioneers of the promotion and dissemination of scientific knowledge in the field of Invasive Physical Therapy. From this point onward, this biennial conference has gathered physical therapists and other interested professionals, in a format that integrates clinical evidence with research and workshops for professional development. This successful model has received institutional support from the university and the Professional Board of Physical Therapy from its onset, declared of interest for health by government bodies and accredited by the Commission of Continued Training for Health Professions (CFCPS) of the Spanish National Health System.

After the first editions held in Madrid in 2014 and 2016, the III International Conference on Invasive Physical Therapy (CIFI 2018) took place in Valencia on October 27 and 28, 2018. For the first time the conference was organized by the Scientific Society of Neuromusculoskeletal Invasive Physical Therapy (SOCIFIN), with collaboration from the Official Board of Physical Therapists of the Community of Valencia (ICOFCV), the University of Valencia and the European University of Valencia.

The Santiago Grisolía auditorium of the Prince Felipe Museum of Science at the City of Arts and Sciences accommodated over 450 professionals from different parts of Spain, Portugal, France, Switzerland, Holland, Belgium, England, Chile, Argentina, Brazil and Colombia. Attendees had the opportunity to update their knowledge on invasive physical therapy and exchange scientific information thanks to participation from 30 national and international speakers in six round tables, and the presentation of over 50 research studies, comprising both oral communications and poster presentations.
Now, there is continuity for the research articles presented at the last conference with the publication of the abstracts of these communications and a selection of these studies as original articles in this second issue for 2019 of the Invasive Physical Therapy Journal. Our commitment to the Scientific Society is to use this journal to disseminate the valuable contributions made by professionals, emphasizing the evidence obtained in clinical research.

The CIFI 2018 revolutionized the traditional concept of a conference, aiming to increase the amount of participation, debate and interaction among speakers, presenters and attendees. For this purpose, the CIFI created new formats, incorporating Fire Debates to the round tables of "Percutaneous needle electrolysis" and "Dry Needling", Vis a Vis in the table of "From the injury to Return to play", and Integrated lectures on the table on "Musculoskeletal ultrasound in physical therapy". This information is also gathered in this issue of the journal, featuring two articles on "clinical application criteria" which gather the clinical know-how of professionals and the expert consensus on this subject.

A new opportunity to support knowledge and seek professional advancement, leaving aside acronyms and commercial interests, will take place on November 7 and 8, 2020 in Porto. For the first time, the $4^{\text {th }}$ edition of the CIFI will be held outside Spain, the country where it was born and where it has developed until reaching its current prestige. The CIFI is a brand recognized by the European Union Intellectual Property Office (EUIPO), which, due to its originality and innovation, has become a reference in the world of physical therapy, to the extent that imitations have arisen, which, far from being an offense, are considered a compliment, as for any brand worth its name, a crude and cheap copy exists.

I hope that this edition may be of great interest to readers, encouraging you to continue participating in the CIFI, a meeting point that is open to all professionals who are involved in the field of Invasive Physical therapy.
Address for correspondence Fermín Valera Garrido, Vicepresident of the Organizing Committee at the III International Conference of Invasive Physical Therapy, 2018, Valencia, Spain (email: ferminvalera@mvclinic.es).
DOI https://doi.org/

10.1055/s-0039-3402509. ISSN 2386-4591.
Copyright $\odot 2019$ by Thieme Revinter Publicações Ltda, Rio de Janeiro, Brazil
License terms

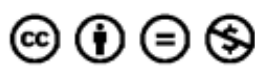

